\title{
Caso clínico. Complicación periprotésica
}

\author{
Clinical case. Peri-prosthetic complication
}

José Manuel Pérez-Atanasio*

* Médico ortopedista, Adiestramiento en reemplazo articular UNAM, maestro en ciencias.

Coordinador de investigación del Hospital Shriners para niños Ciudad de México.

Correspondencia: Dr. José Manuel Pérez-Atanasio. Calle Tanka No. 153, Col. Fraccionamiento Grand Juriquilla,

C.P. 76226, Querétaro, Querétaro. Correo electrónico: drmanuelperezata@gmail.com

Se presenta el caso clínico de un paciente de 68 años de edad sin antecedentes de patologías crónico degenerativas, con diagnóstico de artrosis de cadera derecha de larga evolución, tratado con una artroplastia total de cadera cementada 10 años previos. Actualmente acude a consulta por presentar dolor de cadera derecha que se acompaña de marcha claudicante, se solicita la radiografía que a continuación se muestra en la Figura 1.

Como se muestra en la Figura 2, se identificó el aflojamiento del componente femoral en todas las zonas de Gruen, ${ }^{1}$ con base en la clasificación de defectos femorales de Paprosky se determinó que tiene un defecto máximo tipo IV, ${ }^{2} \mathrm{y}$ con respecto al acetábulo se clasificó como un defecto tipo A de Paprosky. ${ }^{3}$

Se decidió realizar una cirugía de revisión con recambio de componentes, la cirugía se efectuó bajo anestesia regional por bloqueo, paciente en posición decúbito lateral y abordaje lateral, se retiraron los implantes y se colocaron componentes no cementados y cerclajes de protección como se muestra en la Figura 3.

Durante su estancia postoperatoria hospitalaria el paciente presentó dolor en el muslo, por lo que se solicitó una nueva radiografía, encontrando una fractura periprotésica de la diáfisis femoral como se muestra en la Figura 4 y se clasificó como tipo B2 de Van-

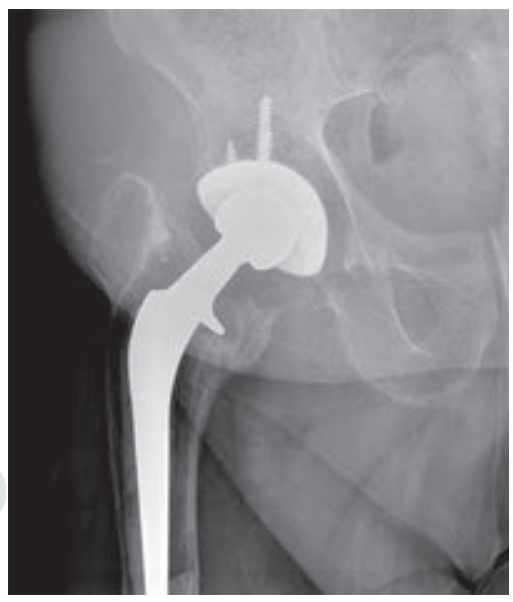

Figura 1: Radiografía anteroposterior de cadera. 
couver. ${ }^{4}$ Cabe mencionar que dicha fractura no fue identificada en el periodo postoperatorio inmediato.

Una vez que se identificó la fractura periprotésica se reoperó al paciente con la colocación de cerclaje, recolocación de componente femoral, el cual se cam-

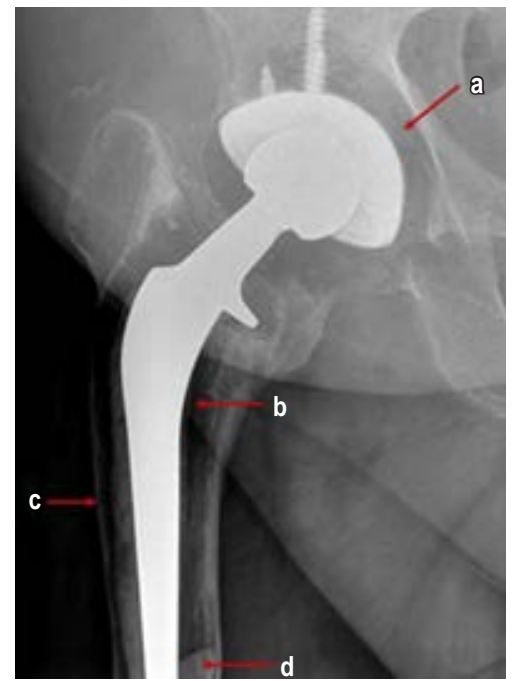

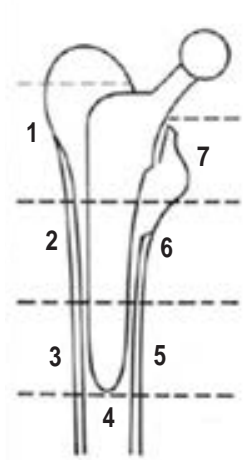

Zonas de Gruen
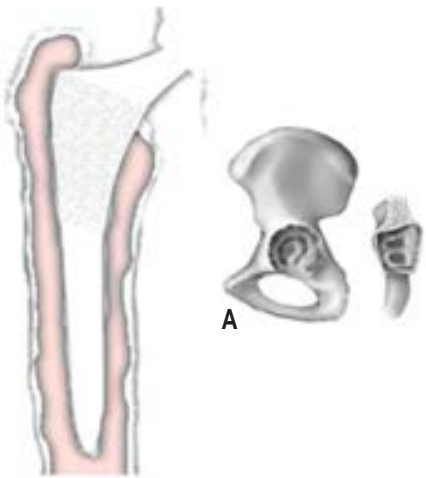

Clasificación de Paprosky

Tipo IV en fémur

Tipo A en acetábulo

Figura 2: Imagen radiográfica anteroposterior de cadera en la que podemos observar: a) zona de aflojamiento acetabular con defecto óseo clasificación Paprosky tipo A, b) Aflojamiento en todas las zonas de Gruen con clasificación de Paprosky para defectos femorales tipo IV, c) Adelgazamiento severo de la cortical lateral del fémur y d) Cemento óseo. Se agregaron las imágenes de las clasificaciones utilizadas con fines didácticos y para pronta referencia.

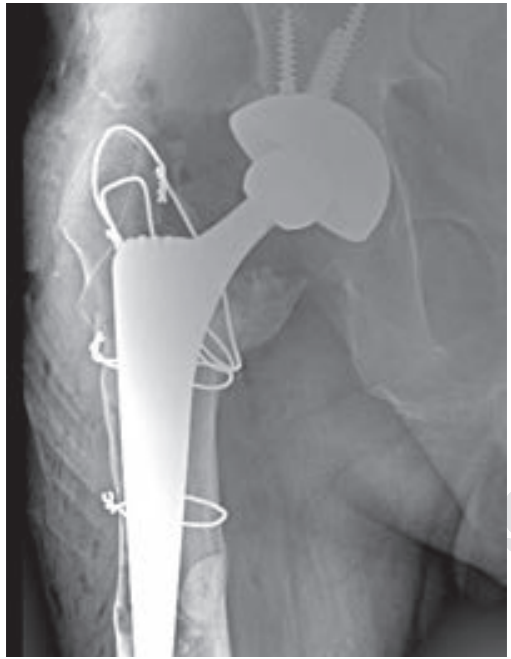

Figura 3: Resultados postquirúrgicos.

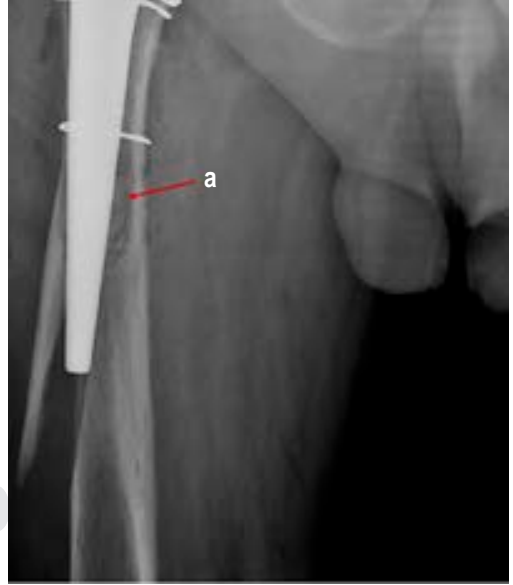

Figura 4: Fractura periprotésica identificada en el periodo postoperatorio. a) Nótese el cemento en el canal femoral que desvió el vástago, lo que propició la fractura. 
bió por un componente cementado, durante el procedimiento se retiró del canal medular el cemento óseo que muy probablemente fue el que desvió el vástago femoral, lo que propició la fractura. El resultado del tratamiento de la fractura periprotésica se observa en la Figura 5.

¿Qué aprendimos de este caso clínico?

Cuando realicemos una cirugía de revisión de componente femoral, además de seguir todos los lineamientos recomendados en la literatura, necesitamos:

- Retirar por completo el cemento de la diáfisis femoral.

- Tomar una radiografía de control en la que se incluya la diáfisis femoral.

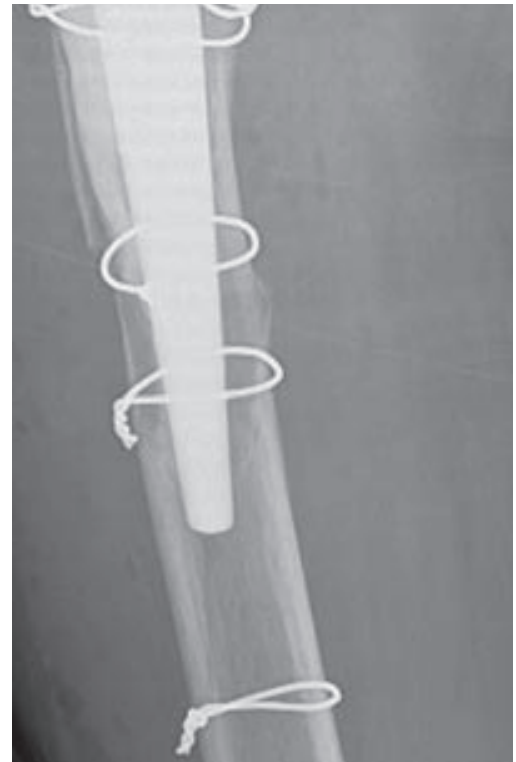

Figura 5: Resultado final del tratamiento de la fractura periprotésica femoral.

\section{BIBLIOGRAFÍA}

1. Gruen TA, McNeice GM, Amstutz HC. 'Modes of failure' of cemented stem-type femoral components: a radiographic analysis of loosening. Clin Orthop Relat Res. 1979; (141): 17-27.

2. Valle CJ, Paprosky WG. Classification and an algorithmic approach to the reconstruction of femoral deficiency in revision total hip arthroplasty. J Bone Joint Surg Am. 2003; 85-A (Suppl 4): 1-6.

3. Paprosky WG, Perona PG, Lawrence JM. Acetabular defect classification and surgical reconstruction in revision arthroplasty: a 6-year follow-up evaluation. J Arthroplasty. 1994; 9: 33-44. doi: 10.1016/08835403(94)90135-X.

4. Parvizi J, Rapuri VR, Purtill JJ, Sharkey PF, Rothman RH, Hozack WJ. Treatment protocol for proximal femoral periprosthetic fractures. J Bone Joint Surg Am. 2004; 86 [Suppl 2]: 8-16. 